\title{
Social and Economic Exchange Between Social Workers and their Employers in the Context of their Sectorial Affiliation and Seniority
}

\author{
Ester Zychlinski $^{1}$ (1) $\cdot$ Dorit Bar-Nir $^{1} \cdot$ Maya Kagan $^{1}$
}

Accepted: 14 October 2021 / Published online: 1 November 2021

(c) International Society for Third-Sector Research 2021

\begin{abstract}
Partial privatization creates organizational hybrids that can generate conflict between professional and institutional logic among social workers. Research is scant but necessary to identify better organizational approaches. Using the social and economic exchange (SEE) model, we examined Israeli social workers' perception of their relationships with their workplaces. To examine organizational affiliation and seniority impact on SEE, we conducted a two-way ANOVA on data from 824 social workers: $55.1 \%$ from government sector (GSO) 30.8\% from 'third sector' (TSO), and $14.1 \%$ from for-profit sector (FPO) organizations. Our findings showed the SEE model identified ways organizations and their social workers manage sector hybridity. Social exchange among TSO social workers was higher than GSOs, but similar to FPOs. Economic exchange was higher in FPOs, compared to GSOs. Seniority related only to economic exchange, possibly signaling change among newer social workers. TSOs must strengthen their social exchange to maintain their advantage among social workers.
\end{abstract}

Keywords Social exchange Economic exchange $\cdot$ Social workers · Sectorial affiliation · Professional seniority

Ester Zychlinski

esterz@ariel.ac.il

Dorit Bar-Nir

doritbarnir@gmail.com

Maya Kagan

mayaka@ariel.ac.il

1 School of Social Work, Ariel University, Ariel, Israel

\section{Introduction}

Recent decades have seen changes in the provision of social care in Israel, as in other western countries, resulting from partial privatization and decentralization processes. These are "top-down" policy-related processes in which the state plays a key role, attempting to achieve key targets such as increased efficiency, reduced government spending, and empowering local communities (Author 2a, 2011; Bel \& Fageda, 2007; Paz-Fuchs, 2018).

These processes have had major implications for frontline social workers' work environments: changing the type of organizations providing social services and changing organizations' institutional logic. Work environments previously identified primarily with government sector organizations (GSOs) are now better described as 'mixed economy'. As Warner (2009) noted, this process shifted from government service delivery to market delivery (third and for-profit sector organizations-TSOs, FPOs), although still financed by the government. Change in the organization types in which social workers provide services has been accompanied by inherent changes in institutional logic to which social workers were accustomed-from GSO logic to the TSO and FPO institutional logic.

According to Vurro et al., (2010:43), "Institutional logics represent the set of formal and informal rules of actions, interactions and interpretations that guide, constrain and are shaped by action, as individuals and organizations act and behave in the different social systems they belong to". It is, therefore, to be expected that social workers' work perceptions will be influenced by the institutional logic that characterizes the sector in which they work. For example, the GSO sector is identified mainly with protection of public interest and lack of profit motives. TSOs in the social welfare field are primarily 
identified with lack of profit motives, democracy, and public participation; FPOs are primarily characterized by free-market values (Hesse et al., 2019; Pache \& Santos, 2013; Zychlinski et al., 2020a, b).

When TSOs start shifting their nature, as discussed by Hasenfeld and Gidron (2005), they strive for varied goals. These so-called hybrid voluntary organizations possess characteristics often correlated with multiple sectors; in their activities, boundaries between the three sectors become blurred (Billis, 2010). One major resulting challenge is the need for reconciliation between their social goals and economic interests (Schmid \& Bar-Nir, 2001). Likewise, hybrid processes, referring to core organizational components not conventionally combined (Battilana et al., 2017), occur not only in TSOs but also in other sectors. Social enterprise organizations are an example of hybrid organizations (Battilana et al., 2015). In social enterprise research regarding work integration in France, where some organizations were FPOs and some TSOs, it was found that all adopted aspects of social welfare and market logic, but FPOs adopted more social welfare logic elements than TSOs in order to increase legitimization (Pache \& Santos, 2013).

Such changes in institutional logic can create challenging work environments for social workers, with blurred boundaries between sectors alongside tensions between them (Billis, 2010; McMullin \& Skelcher, 2018; Perez, 2019). Conflict resulting from hybrid institutional logic can be characterized into four types: contested (extensive conflict), estranged (moderate conflict), aligned (minimal conflict), or dominant (no conflict) (Besharov \& Smith, 2014). Successful incorporation of competing sets of institutional logic, like social welfare and market logic, could depend on strategic decisions to selectively couple intact elements from each logic, for instance, to reduce costs and increase external perception of legitimacy (Pache $\&$ Santos, 2013). Accordingly, the tendering policy has resulted in adoption by TSOs and FPOs of values important in GSOs (e.g., public interest, aspiration for meaning) in order to meet tender requirements. Similarly, FPO values (e.g., competition, efficiency, entrepreneurship) have penetrated GSOs due to the New Public Management approach reflected in tenders (Abramovitz \& Zelnick, 2018), with TSOs also assimilating these values to compete with FPOs in receiving government tenders.

Accordingly, social workers must manage organizational values unfamiliar to them and sometimes contradict professional values, such as providing adequate client care under expectations of efficiency and profit (Abramovitz \& Zelnick, 2018). Despite significant redefinition of social workers' work environments, few studies have examined the impact of sectoral affiliation on social workers' perceptions of this novel hybridity (Borzaga \& Tortia, 2006;
Freund, 2005; Jiang et al., 2019) and only Freund (2005) examined all three sectors.

Studies have examined employees' perceptions of their relationships with employers, attempting to characterize conditions encouraging employee motivation and promoting workplace commitment (Buch et al., 2013, 2019; Dysvik et al., 2015; Kuvaas et al., 2020). Studies have also examined general differences between the three sectors (McMullin \& Skelcher, 2018), their degree of hybridity (Pache \& Santos, 2013), and their ability to balance social missions and market perceptions (Mikolajczak, 2020). However, research specifically focusing on social workers is scant and neglects exploration of perceptions of their social and economic exchange with their employers. One of the main theoretical frameworks for examining the employee/employer relationship is the social exchange theory (Blau, 1964; Emerson, 1976) which inspired development of the Social and Economic Exchange (SEE) model by Shore et al. (2006). The SEE model, described below, explains how, for instance, differences between social worker perceptions can reflect the extent to which they believe their workplace effectively manages the balance between their social mission (expressed in a 'social exchange') and their economic focus (expressed in an 'economic exchange').

Social and economic exchange research is highly relevant to this research topic. It can identify factors impacting social workers' wellbeing, including their specific needs; this may, in turn, have a downstream impact on clients affected by their social workers' attitudes and practices (Ng, 2010), and also assist the three sectors better retain their employees. SEE research can also provide policymakers with additional perspectives when considering the continued implementation of the partial privatization policy. Therefore, the present study attempts to characterize front-line social workers' perception of their relationships with their employers, exploring possible associations with their seniority and sectorial affiliation, through the model of social and economic exchange. To answer the research hypothesis, a two-way ANOVA was conducted to examine the effects of organizational affiliation and seniority on social and economic exchange among social workers.

The remaining sections of this article are organized as follows: the next three sections present the theoretical bases on which the research hypotheses were derived, the fourth presents the hypotheses, and the fifth presents the method and findings. Finally, the research contribution, its limitations, and suggestions for further research are presented. 


\section{The Institutional Logic of the Three Sectors and the Values of Social Work}

In Israel, as in the vast majority of Western countries, front-line social workers are employed in three sectors: the GSO sector, which includes the central and local government; the FPO sector, which includes private business; and the TSO sector, which includes private non-profit organizations (Gidron et al., 2004). Most of the social workers in Israel are affiliated with the GSO sector, followed by the TSO, and only a small proportion in the FPO (Freund, 2005; Israeli Association of Social Workers, 2018a, 2018b).

Each sector maintains a different institutional logic, which refers to "the cultural beliefs, norms of behavior and rules that inform decision making within organizations" (McMullin \& Skelcher, 2018: 912). Decision-making includes material issues regarding organizational structure and practices but also symbolic issues such as organizational assumptions, beliefs, and identities (McMullin \& Skelcher, 2018). Institutional logic influences the perceptions and behavior of organizational 'actors' (Ngoye et al., 2019), by helping them reach decisions based on the sector's dominant logic (Mikolajczak, 2020). Therefore, differences in social workers' perceptions can be expected according to their sectorial affiliation.

The logic associated with the bureaucratic state (GSO) concerns the supervision of human activity, legal and bureaucratic hierarchies, procedures, and standards for implementation of organizational processes (Bryson et al., 2006). The GSO sector is identified with the "guardian syndrome", which includes values such as avoiding engagement in commerce, lack of profit motives, aspiration for meaning, supremacy of the public interest, loyalty and respect for tradition and hierarchy, and tendency toward continuity (Klijn \& Teisman, 2004). GSOs "are owned by citizens and state and their activities are funded with taxes" (Mikolajczak, 2020: 475).

The logic of the TSO sector in democratic and welfare states emphasizes the lack of profit motives, inclusive participation, and the public's ability to control decisionmaking through volunteerism and civic participation such as voluntary associations (Bryson et al., 2006). Despite this, there are also TSOs established by governments or businesses as part of their corporate social responsibility (CSR) strategy (Gidron et al., 2004). Indeed, it is a discussion in Israel who is considered a true third sector organization, primarily characterized by civic participation. In addition, TSOs emphasize legitimization arising from public trust, reciprocity, and cooperation between individuals within shared geography or common set of goals and values (McMullin \& Skelcher, 2018). TSOs are "owned by their members, they employ a team of employees, engage volunteers and generate revenues primarily from membership, fees, donations, collections, and public funds" (Mikolajczak, 2020: 475).

FPO sector logic includes material practices of hoarding, ownership, competition, and efficiency (Bryson et al., 2006). FPOs are identified by a commercial concept that appreciates fairness, enthusiasm, and entrepreneurship (Klijn \& Teisman, 2004), but maximizing shareholder value is their primary purpose (Ashraf et al., 2017).

As a result of the partial privatization and decentralization policy (Author2, 2011; Benish, 2018; Lu and Xu, 2018), TSOs and FPOs are dependent on revenues from government tenders, payments by service recipients, and, for TSOs, donations as well (Schmid, 2013). This has caused mutual influence between various institutional logic types and produced organizations characterized by the logic of several sectors concurrently (Bellis, 2010; McMullin \& Skelcher, 2018). Since front-line social workers are organizational actors (Ngoye et al., 2019), they may be influenced by the institutional logic of the sector in which they are employed, sometimes in conflict with the core values of the profession (professional logic). Professional logic refers to unique organizing principles, practices, and symbols that influence individual and organizational behavior (Thornton et al., 2012); in social work, it emphasizes concern for discretion, public benefit, social wellbeing of service users, and building ongoing trusting relationships between social workers, individuals, and communities as a basis for promoting change (Smith, 2004). However, Mikolajczak (2020) cites a study conducted in Poland (Hensel, 2015) that emphasizes when professional logic is confronted by another logic that has become recognized and dominant in society, such as market logic, professional logic tends to weaken. In light of these tensions between institutional and professional logic, one may reasonably predict different perceptions from social workers towards their employers based on sectorial affiliation.

\section{The Social and Economic Exchange Model}

The social exchange theory argues that relationships take place within the framework of the economic "market", in which material and symbolic goods are commuted between two or more social actors (persons, groups, organizations), to benefit each party (Blau, 1964; Levine \& White, 1961). Such 'exchange relationships' can be based on formal contracts that determine conditions and procedures, or be informal such as interactions between friends, neighbors, and even romantic relationships (Blau, 1964). These relationships are characterized by continuous, repetitive 
activities between the parties for short or prolonged periods (Blau, 1964). The balance between give and take (Schaufeli, 2006) depends on the reward (value) and the cost transferred to each side through reciprocal exchange. The exchange theory identifies two main types of exchange: social and economic. On this basis, Shore et al. (2006) developed an integrative and comprehensive model known as the Social and Economic Exchange model, which makes it possible to examine how employees perceive their social and economic exchange with their employer concurrently (Buch et al., 2019).

Social exchange is interpretative and context-related (Kim et al., 2005). In a social context, two parties must each assume some risk because their relationship is not based on a clear contract; therefore, trust and investment are intertwined. The relationship tends to be ongoing, has a longer-term orientation, and develops when both parties reciprocate the receipt of valued resources (Shore et al., 2009). In this kind of relationship, the emphasis is on socio-emotional aspects such as "give and take" and "being taken care of" (Shore et al., 2006), and the relationship is characterized by each party's expectations for future return, though its form and time of repayment are unclear (Buch et al., 2013). Therefore, in a workplace setting, an employee with a higher level of perceived social exchange may feel greater support for the organization's mission, valued by the employer, willing to sacrifice for organization's goals, trust that their work will eventually be acknowledged, greater confidence in the organization, while a lower level implies the opposite. Higher levels of social exchange have been found to be associated with higher levels of affective commitment in the workplace (Shore et al., 2006) and greater levels of organizational commitment (Liu \& Deng, 2011).

Economic exchange, in contrast, is characterized by economic agreement in quid pro quo fashion (e.g., pay and benefits) (Zhu, 2012) and by specified contracts or obligations. As described by Shore et al., (2009: 290), “...the parties are confident that each party will fulfill his/her obligations based on societal norms of economic exchange between employee and employer (e.g., a fair day's work for a fair day's pay)". Economic exchange tends to imply shorter-term relationships defined by calculus-based trust and a transactional, contractual character over interpersonal attachment. The form and timing of the reward are clearer, so the trust required is less strongly tied to the relationship itself. Therefore, in a work setting, employees with higher levels of economic exchange are more heavily focused on their self-interest (e.g., wages, benefits, work conditions), than the organizational needs (Buch et al., 2013, 2019; Dysvik et al., 2015; Kuvaas et al., 2020; Shore et al., 2006; Zychlinski et al., 2020a, b). Higher economic exchange was found to be associated with a greater continuance commitment in organizations in which employees had no other employment options (Akbar et al., 2018; Meyer \& Parfyonova, 2010; Shore et al., 2006).

Thus, employee perception of higher social exchange indicates mutual trust, confidence, commitment, and reciprocity: it is beneficial to employee and employer. In contrast, employee perception of higher economic exchange indicates focus on one's gains: this is primarily beneficial to employees unless organizations value highly contractual, transactional, or temporary employee relationships.

As social workplaces high value on social exchange (e.g., long-term relationships, trust), its professional logic may be more compatible with GSO and TSO, than FPO, logic. Moreover, social work stresses the public good and overlooks the importance of material interests (Luo \& Chui, 2020; Ng, 2010), a feature that may reduce the involvement of social workers in economic exchange. Indeed, few studies found wage a central variable for work satisfaction among social workers (Luo \& Chui, 2020). According to Schweitzer et al. (2013), social workers prefer payment by salary over other payment types (e.g., fee-for-service, contract payments, and insurance reimbursement), suggesting it reflects a preference toward job stability. Job stability in Israel is ensured mainly by GSOs, in which salaries are paid regularly from government revenues (Paz-Fuchs, 2018). Thus, while social workers in GSOs may be less involved in economic exchange than other sectors because TSO logic also prioritizes civic participation and lack of profit motives this may also reduce their social workers' involvement in economic exchange. In contrast, FPO social workers, likely affected by the profit orientation, may be more involved in economic exchange than the other sectors.

Another factor potentially affecting the social worker employee/employer exchange is professional seniority and this factor is described below in more detail.

\section{Professional Seniority}

Seniority reflects years of work in the field, namely a longterm relationship. Previous studies found that social worker seniority is associated with a wide range of positive psychosocial implications in the work environment. For example, a negative association was found between years of professional experience and social worker psychological distress (Kagan \& Itzick, 2017). Older social workers display greater job satisfaction, lower turnover intention, higher motivation levels (Itzick \& Kagan, 2016; Jiang et al., 2017; Oppenheim-Weller et al., 2017), and earn higher wages (Schweitzer et al., 2013). Interestingly, in Israel, social workers with greater seniority were found 
more often in the GSO sector than the two sectors (Freund, 2005).

According to the socio-economic exchange model, workplace relationships that develop over time tend to be characterized by trust and loyalty (Cropanzano \& Mitchell, 2005); indeed, studies often examine seniority/tenure as a control factor (Kuvaas et al., 2017). Therefore, our hypothesis was that social workers with more seniority, regardless of sector, would evidence a greater degree of social exchange; consequently, we expected their economic exchange level to be more limited, possibly due to fear of losing economic assets accumulated over a longer period of time, or due to having fewer employment alternatives (Shore et al., 2006). Moreover, since seniority is an important factor in social work, related to a more established professional identity (Shim et al., 2009), we predicted that the professional logic of senior social workers would be more integrated and have greater influence on their perception of social and economic exchange.

\section{Research Hypotheses}

Our research hypotheses focused on the main effects, and interactions between, social worker sectorial affiliation (GSO, FPO, or TSO) and seniority on their perception of the social and economic exchange between themselves and their employers.

\section{Main Effects}

\section{Sectorial Affiliation}

$\mathrm{H}_{1(\mathrm{a})}$ : Differences would be found between social workers with diverse sectorial affiliations (GSO, FPO, TSO) with regard to social and economic exchange. Social workers in GSOs and TSOs would report higher social exchange than those in FPOs. Social workers in FPOs would report higher economic exchange than those in GSOs and TSOs.

\section{Seniority}

$\mathrm{H}_{1(\mathrm{~b})}$ : Differences would be found between social worker seniority levels with regard to social and economic exchange. Social workers with a high seniority level would report higher social exchange than social workers with moderate and low seniority. Social workers with high seniority would report lower economic exchange than social workers with moderate and low seniority levels.

\section{Interaction Effects}

$\mathrm{H}_{1(\mathrm{c})}$ : An interaction effect would be found between sectorial affiliation and seniority levels. At a high seniority level, social workers in GSOs and TSOs would report higher social exchange and lower economic exchange than social workers in FPOs.

\section{Method}

\section{Research Population and Sample}

The current study included 824 front-line Israeli social workers working in GSOs, TSOs, and FPOs. The cohort included $142(17.3 \%)$ men and $679(82.7 \%)$ women, whose mean age was $37.47(S D=10.25)$ and mean years of seniority was $10.81(S D=9.51)$. Of the entire sample, 454 $(55.1 \%)$ social workers were working in GSOs, 254 $(30.8 \%)$ in TSOs, and $116(14.1 \%)$ in FPOs.

The GSO cohort was $70(15.5 \%)$ men and $383(84.5 \%)$ women whose mean age was $39.36(S D=10.74)$ and mean years of seniority was $12.63(S D=10.13)$. The TSO cohort was $53(21 \%)$ men and $199(79 \%)$ women whose mean age was $35.66(S D=9.4)$ and mean years of seniority was 8.95 $(S D=8.28)$. The FPO cohort was $19(16.4 \%)$ men and 97 $(83.6 \%)$ women whose mean age was $34.17(S D=8.47)$ and mean years of seniority was $7.77(S D=7.19)$.

\section{Sampling Methods and Procedure}

The current study received University institutional ethics committee approval for nonclinical research in humans. The data were collected via structured questionnaires. By random sampling, each person in the research cohort had an equal chance of being sampled at each stage of the sampling process. This requires information about the general population of social workers in Israel currently engaged in the social work profession. Although all social workers in Israel are registered with the Registrar of Social Workers at the Ministry of Labor, Social Affairs, and Social Services, their contact information is kept confidential. Furthermore, there is no database differentiating between social workers by current engagement in the social work profession or by workplace, precluding random sampling of this population. Accordingly, research assistants, third-year social work students, used alternative methods to locate potential respondents. Since all research assistants conduct practical training in places in which social workers are employed (e.g., social services departments, hospitals, nursing homes, boarding schools), they first distributed questionnaires among the social workers employed in these settings. Then, adopting a snowball 
sampling method, they asked those social workers to contact their colleagues from other places as possible respondents. Snowball sampling is usually used in cases in which it is necessary to sample subjects from populations to which access is rather limited and complicated (e.g., in the absence of a sampling frame or public information regarding potential subjects' contact information) and also when there is a reasonable basis to assume that people in this population know others within it (e.g., social workers knowing other social workers). Some respondents completed questionnaires in the presence of research assistants while others preferred to complete and return them later. To maintain complete anonymity, all questionnaires were sealed in opaque envelopes immediately after completion and research assistants were instructed not to data-enter questionnaires collected at their own training places, but rather transfer them to other members of the research team for processing.

To expand the scope of social workers recruited for the research, questionnaires were also uploaded to diverse social networks targeting social workers, such as professional forums and Facebook ${ }^{\circledR}$ pages. While the rate of consent to participate in the study was about $80 \%$ of all social workers approached directly, it was not possible to assess the online response rate as the rate of exposure to the research on the internet was unknown. An informed consent statement was attached to all questionnaires (in both printed and online versions), explaining the study's purpose and requesting their consent to participate. The document included the primary researchers' contact information, noting they could be contacted if questions arose or clarifications were necessary while completing questionnaires.

\section{Research Tools}

\section{Dependent Variables}

Economic and social exchange between employees and employers was assessed by a scale developed by Shore et al. (2006). The economic exchange index was assessed by calculating the mean of eight statements, ranked on a scale of 1 (strongly disagree) to 5 (strongly agree), relating to economic exchange, such as "My relationship with my organization is strictly an economic one. I work and they pay me" and "All I really expect from my organization is that I am paid for my work effort." Reliability and internal consistency of this scale were 0.76 . The social exchange index was also assessed by calculating the mean of eight items ranked on a scale of 1 to 5 , with statements relating to social exchange, such as "Even though I may not always receive the recognition from [my organization] that I deserve, I know my efforts will be rewarded in the future" and "My relationship with [my organization] is based on mutual trust." Reliability and internal consistency of this scale were 0.77 .

\section{Independent Variables}

Sectorial affiliation - Respondents were asked to note in which sector they work: GSOs, FPOs, or TSOs.

Seniority - Social workers were asked their years of seniority in the profession. To include this variable in a two-way ANOVA, it was divided into three categories: (1) Workers with less than 5 years of seniority were categorized as 'low seniority'; (2) Workers with 5 to 10 years of seniority were categorized as 'moderate seniority'; (3) Workers with 10 or more years of seniority were categorized as 'high seniority'. These durations were chosen in consideration of how social work seniority typically functions in Israel: (1) In GSOs, social workers are given courses and close guidance during their first years in the field; (2) Social workers can only become field training instructors after at least 5 years in the field and instructor course completion; and (3) To become a social work 'expert' according to the Ministry of Social Affairs and Association of Social Workers (2014), social workers must have at least 10 years of seniority.

Demographics - In order to describe the sample, respondents were asked to note their gender and age.

\section{Results}

Based on the Shapiro-Wilk test, the dependent variables (social and economic exchange) displayed a normal distribution for the groups formed by combining respondents' sectorial affiliation and seniority. The Levene test for equality of variances indicated homogeneous variance between the groups on all variables. Means and standard deviations of social and economic exchange, segmented by social worker sectorial affiliation and seniority, are presented in Table 1. The results of a two-way ANOVA to examine main and interaction effects of sectorial affiliation and seniority on social and economic exchange among the social workers are presented in Table 2.

\section{Main Effects}

\section{Sectorial Affiliation}

The main effect was found by sectorial affiliation, for social exchange $\left(F_{(2,813)}=6.71, \quad p<0.01, \quad\right.$ partial $\left.\eta^{2}=0.016\right)$ and economic exchange between social workers and their employers $\left(F_{(2,812)}=3.77, p<0.05\right.$, partial $\left.\eta^{2}=0.009\right)$. To examine the variation's source, 
Table 1 Distribution of social and economic exchange between employees and employers among social workers, by sectorial affiliation and seniority

\begin{tabular}{|c|c|c|c|c|c|}
\hline \multirow[t]{2}{*}{ Sectorial Affiliation } & \multirow[t]{2}{*}{ Seniority } & \multicolumn{2}{|c|}{ Social exchange } & \multicolumn{2}{|c|}{ Economic exchange } \\
\hline & & Mean & SD & Mean & SD \\
\hline \multirow[t]{4}{*}{ Government sector (GSO) } & Low & 3.06 & 0.66 & 2.04 & 0.63 \\
\hline & Moderate & 2.91 & 0.61 & 2.20 & 0.66 \\
\hline & High & 2.92 & 0.66 & 2.02 & 0.65 \\
\hline & Total & 2.96 & 0.65 & 2.07 & 0.65 \\
\hline \multirow[t]{4}{*}{ Third sector (TSO) } & Low & 3.07 & 0.71 & 2.28 & 0.62 \\
\hline & Moderate & 3.20 & 0.67 & 2.04 & 0.62 \\
\hline & High & 3.14 & 0.75 & 2.02 & 0.60 \\
\hline & Total & 3.13 & 0.71 & 2.13 & 0.62 \\
\hline \multirow[t]{4}{*}{ For-profit sector (FPO) } & Low & 3.02 & 0.66 & 2.34 & 0.58 \\
\hline & Moderate & 3.27 & 0.83 & 2.34 & 0.70 \\
\hline & High & 3.19 & 0.75 & 2.13 & 0.50 \\
\hline & Total & 3.14 & 0.74 & 2.29 & 0.60 \\
\hline \multirow[t]{4}{*}{ Total } & Low & 3.05 & 0.68 & 2.19 & 0.63 \\
\hline & Moderate & 3.06 & 0.68 & 2.17 & 0.66 \\
\hline & High & 3.00 & 0.69 & 2.03 & 0.63 \\
\hline & Total & 3.04 & 0.68 & 2.12 & 0.64 \\
\hline
\end{tabular}

Table 2 Results of a two-way ANOVA examining the effect of sectorial affiliation and seniority on social and economic exchange between employees and employers among social workers

\begin{tabular}{llllllll}
\hline & Source of variation & Df & Sums of squares & Mean square & F & p & Partial Eta squared \\
\hline Social exchange & Sectorial affiliation & 2 & 6.175 & 3.087 & 6.710 & .001 & .016 \\
& Seniority & 2 & .674 & .337 & .733 & .481 & .002 \\
& Sectorial affiliation $\times$ Seniority & 4 & 3.667 & .917 & 1.992 & .094 & .010 \\
& Error & 813 & 374.079 & .460 & & & \\
Economic exchange & Sectorial affiliation & 2 & 3.010 & 1.505 & 3.769 & .023 & .009 \\
& Seniority & 2 & 2.918 & 1.459 & 3.654 & .026 & .009 \\
& Sectorial affiliation $\times$ Seniority & 4 & 4.443 & 1.111 & 2.782 & .026 & .014 \\
& Error & 812 & 324.253 & .399 & & & \\
\hline
\end{tabular}

post hoc Scheffe tests were performed. The findings indicate the hypothesis was only partially confirmed: GSO social workers $(M=2.96, S D=0.65)$ reported lower levels of social exchange than social workers affiliated with TSOs $(M=3.13, S D=0.71)$ and FPOs $(M=3.14, S D=$ 0.74). Also, GSO social workers $(M=2.07, S D=0.65)$ reported lower levels of economic exchange than FPO social workers $(M=2.29, S D=0.61)$.

\section{Seniority}

Seniority was found to have a main effect only for economic exchange between social workers and their employers $\left(F_{(2,812)}=3.65, p<0.05\right.$, partial $\left.\eta^{2}=0.009\right)$. Scheffe's post hoc tests revealed that high seniority social workers $(M=2.03, S D=0.64)$ displayed lower levels of economic exchange than social workers with low $(M=2.19, S D=0.63)$ and moderate seniority $(M=2.17$, $S D=0.66)$. These findings indicate that the hypothesis was only partially confirmed.

\section{Interaction Effect}

The hypothesis concerning an interaction effect between sectorial affiliation and seniority regarding social exchange was not confirmed. However, as hypothesized, a significant interaction effect was found between sectorial affiliation and seniority, but only for economic exchange $\left(F_{(4,812)}=2.78, p<0.05\right)$. To determine the interaction's source, one-way ANOVAs were conducted among the three sectorial affiliations (GSO, TSO, FPO) separately. 
In GSOs, social workers with moderate seniority $(M=2.2, S D=0.66)$ were found to display higher levels of economic exchange than high seniority social workers $(M=2.01, \quad S D=0.65) \quad\left(F_{(2,451)}=3.34, \quad p<0.05\right) . \quad$ In TSOs, social workers with low seniority $(M=2.28, S D=$ $0.62)$ displayed higher levels of economic exchange than high seniority $(M=2.02, S D=0.60)$ and moderate seniority $(M=2.04, \quad S D=0.62) \quad$ social workers $\left(F_{(2,252)}=5.15, p<0.01\right)$. No differences were found among the various levels of seniority among FPOs $(p>0.05)$.

Examining the interaction from another direction by a one-way ANOVA conducted among the three levels of seniority separately revealed that only at low levels of seniority did social workers affiliated with GSOs $(M=2.04, S D=0.63)$ report lower levels of economic exchange than social workers affiliated with TSOs $(M=2.28, S D=0.62)$ and FPOs $(M=2.34, S D=0.58)$ $\left(F_{(2,268)}=6.43, p<0.01\right)$.

\section{Discussion}

The present study examined Israeli front-line social workers' perceptions of their exchange relationships with their employers, and any impact associated with their seniority and sectorial affiliation, through the model of social and economic exchange (Shore et al., 2006). The study findings indicate several differences between sectors: a most noticeable finding was the lower level of social exchange between GSO social workers and their employers compared to other sectors.

At the outset, the institutional logic of GSOs and TSOs was predicted to be more compatible with the values of the social work profession. However, the findings indicate the opposite, that GSO social workers had the lowest social exchange rate of all sectors. A possible explanation may be that, as a result of partial privatization and decentralization processes, GSO social workers' therapeutic-professional roles were transferred to TSO and FPO social workers. Doing so has added considerable bureaucratic work to GSO employees now relying on work outsourced to TSOs (BarNir, 2011; Burnley et al., 2005; Nelson, 2005). Milward and Provan (2000) described this arrangement as a "Hollow State", a metaphor for the changing role of the government as a result of the decentralization or devolution of public service delivery. The growing dependence of the government on third parties (TSOs and FPOs) for social service delivery renders the state "hollow", as it outsources its functions to external bodies. Indeed, Warner (2009) describes decentralization and privatization as two processes united in minimizing the government's role and increasing its dependence on non-governmental entities.
Thus, both processes and the "hollowing out" of the state are interconnected. This can lead to a wide impact on governmental worker conduct; for example, Wang (2013) found that hollow state initiatives negatively impacted the performance-based felt accountability of government (federal civil) servants. These changes represent a change in GSO institution logic due to the market logic adopted through policies like privatization, decentralization, and New Public Management. This change in governmental sector organization logic is in contradistinction to the professional logic of social work and probably leads to a loss of trust and disappointment in the workplace, reflected in perception of lower levels of social exchange.

Although TSOs too are undergoing changes that increase bureaucratic work among social workers due to partial privatization (Abramovitz \& Zelnick, 2018), studies have shown that the level of investment and sense of efficacy among TSO social workers is higher than in GSOs (Auerbach et al., 2010; Freund \& Tzriker, 2016). As TSO values are known to emphasize social ideologies and activities (e.g., citizen participation) (Freenstra, 2018), their organizational activities may be publicly perceived as more 'legitimate' (McMullin \& Skelcher, 2018), contributing to the notion that TSO social workers have a better reputation (Freund, 2005; Suh, 2018). In turn, this notion may strengthen the social exchange between TSO social workers and their employers.

The absence of differences between social workers in TSOs and FPOs with regard to social exchange might be related to boundary-blurring inherent in the hybridity concept (Freenstra, 2018). Following privatization and decentralization processes enabling transfer of values from one sector to another (Bryson et al., 2006), market logic (reflected in marketization of welfare services, managerialism, efficiency, and value for money) became assimilated within GSO tenders (Abramovitz \& Zelnick, 2018). Since TSO and FPO sectors must accommodate GSO tender terms, both must adopt social and economic values that previously characterized the other sectors (Bar-Nir, 2001; Schmid, 2020).

Additionally, hybridity may also explain the lack of differences in social exchange between the various levels of seniority: regardless of sector, social workers in Israel have similar professional ethics (Freund, 2005; Freund et al., 2019). This trend is in contrast to an expected erosion of professional logic when confronted by a dominant institutional logic like market logic. It is important to examine these findings in further studies and the extent to which they also characterize other types of professions.

In GSOs in Israel, social workers' salary conditions and opportunities for tenure are guaranteed by wage agreements with the Association of Social Workers (Paz-Fuchs, 2018). Thus, the lack of differences between social workers 
in GSOs and TSOs regarding economic exchange may be due to application of the collective agreement in 2018 (Israeli Association of Social Workers) whose purpose was equalization of social worker wage conditions in privatized social services to those of local government social workers (Ng, 2010; Shlosberg et al., 2017). The agreement applies to any social worker employed by an organization (whether TSO or FPO) that provides services to a government ministry and whose employment is required in accordance with tender terms. The agreement does not apply to social workers involved in activities unassociated with government tenders; therefore, it applies to most TSO, but less FPO, social workers (Heruti-Sober, 2018).

Similarities in economic exchange levels between GSO and TSO social workers may also be explained other factors such as the tendency of TSO workers to focus on 'the mission' rather than on wages (Suh, 2018) and the common non-promotion of profit objectives between these two sectors' institutional logic (McMullin \& Skelcher, 2018). In FPOs, in which the value of promoting profit is more visible and legitimate in terms of the sector's institutional logic, social workers might be more aware of their material interests and thus promote higher levels of economic exchange.

Finally, according to Be'land and Koreh (2019), it is also important to view the GSO sector within the geopolitical context of Israel, where government-supplied social programs served as state-building tools in the past. Similarly, Jewish TSOs distributing or utilizing donations to remedy needs in Israel also served this purpose. Therefore, social workers in GSO and TSO sectors may consider their work a contribution to the construction and defense of the State, and less a tool for generating personal economic profit. Hence, they are less engaged in lower levels of economic exchange with their employers. Further research is needed to test these notions.

The research findings indicate that social workers with low seniority in GSOs are less engaged in economic exchange than similar social workers in TSOs and FPOs. This may indicate greater satisfaction with GSO salaries, work conditions, and benefits (Paz-Fuchs, 2018) that consequently engenders less focus on economic exchange.

Overall, it was evident that social workers in each sector experienced a different relationship to economic exchange, perhaps suggesting that, despite the hybridity processes (McMullin \& Skelcher, 2018), there are still differences between sectors. It may also be indicative of changes among social workers regarding their focus on benefiting materially from the workplace (Luo \& Chui, 2020).

In summary, the present study reinforces and expands previous research. The social and economic exchange (SEE) model enabled a focus on organizations' internal labor relations and identification (through employees' perceptions) of ways in which each sector manages a hybrid situation. The SEE model is suitable for examining the ongoing struggle between employee trust in their workplace's social mission and their personal economic interest, as reflected in their perceptions of social and economic exchange.

There seem to be blurred boundaries between sectors, as expressed in the similarities in social exchange levels between TSOs and FPOs and in economic exchange levels between GSOs and TSOs. Nevertheless, it seems the sectors still retain their own institutional logic as manifested in the different interactions between seniority and economic exchange in each sector.

Despite the changes experienced by social workers due to partial privatization, professional logic in Israel still appears solid, as no association was found between social exchange and seniority. Notwithstanding, the lower the seniority, the more engagement in economic exchange; this trend may suggest a sea-change among young social workers who, despite their professional idealism and altruism, are not willing to tolerate low salaries and job insecurity. This development, along with evolving changes resulting from novel, sometimes conflictual, interactions between professional and institutional logic across different sectors, may explain the higher social exchange level of social workers in TSOs and clarify the growing similarities between TSOs and FPOs. This situation (GSO social workers' comparatively lower levels of social exchange combined with similar wage conditions to the TSO/FPOs due to the application of the collective agreement in 2018) may encourage social workers in Israel to work primarily in TSOs or FPOs, rather than in GSOs.

Nonetheless, circumstances may change due to the COVID-19 pandemic since, at least in Israel, the government is encountering difficulties meeting its current obligations to TSOs (Shmid, 2020). It also seems that if TSOs wish to maintain their uniqueness in the eyes of social workers, they should continue to invest in, and strengthen their organizations' social exchange value. Lastly, it is recommended that GSOs increase employee participation in policymaking to increase their social workers' organizational trust level.

\section{Limitations and Recommendations for Further Research}

Since there is no uniform database in Israel recording social workers' sectorial affiliation, the study employed a convenience sampling and thus, despite the relatively large sample size, it is unclear whether it accurately represents the entire population of social workers in Israel. The findings of the study highlight that TSO and FPO social workers perceive their social exchange with their 
employers as higher (better) than that of GSO social workers. It would behoove future studies to understand the reasons for differences found between the sectors with regard to organizational commitment, continuance commitment, and dual obligations to both the organization and the clients. Additionally, the gender distribution in the study is very skewed, mostly comprised of women. While inherent to social work, it would still be beneficial to examine in future studies whether there are differences in social and economic exchange among male and female social workers.

In addition, the research findings show that, at least among social workers, seniority is associated with lower economic exchange but has no association with social exchange. Perhaps higher seniority reduces social workers' focus on their economic interests but does not affect their level of professional commitment. However, there is need for further studies to examine this topic further. Future research should also examine client satisfaction in all sectors to clarify the impact of social workers' social and economic exchange perceptions, and conduct similar studies in other countries, taking into consideration their social systems and organizational structures.

Funding No funding was received for conducting this study.

\section{Declarations}

Conflict of interest The authors have no relevant financial or nonfinancial interests to disclose.

Ethical Approval The current study received the approval of the institutional ethics committee at Ariel University for nonclinical research in humans.

\section{References}

Abramovitz, M., \& Zelnick, J. (2018). The logic of the market versus the logic of social work: Whither the welfare state? Social Work and Society International Online Journal, 16(2), 1-11.

Akbar, A., Rasshid, M. A., \& Farooq, O. (2018). The relationship between high performance work system and continuance commitment to change: An economic exchange perspective. Journal of Management Sciences, 5(1), 3-17.

Ashraf, N., Ahmadsimab, A., \& Pinkse, J. (2017). From animosity to affinity: The interplay of competing logics and interdependence in cross-sector partnerships. Journal of Management Studies, 54(6), 793-822.

Auerbach, C., McGowan, B. G., Ausberger, A., Strolin-Goltzman, J., \& Schudrich, W. (2010). Differential factors influencing public and voluntary child welfare workers intention to leave. Children and Youth Services Review, 32, 1396-1402.

Bar-Nir, D. (2011). The relationship between a local authority and non-profit organization - An analysis of the power relationship (Doctoral Dissertation). The Hebrew University, Jerusalem. (Hebrew).
Bar-Nir, D., \& Gal, J. (2011). Who has the power? The role of NPOs in local Authorities. Voluntas, 22, 1-25.

Battilana, J., Besharov, M., \& Mitzinneck, B. (2017). On hybrids and hybrid organizing: A review and roadmap for future research. In R. Greenwood, C. Oliver, T. B. Lawrence, \& R. E. Meyer (Eds.), The SAGE Handbook of organizational institutionalism (pp. 128-162). Thousand Oaks.

Battilana, J., Sengul, M., Pache, A.-C., \& Model, J. (2015). Harnessing productive tensions in hybrid organizations: The case of work integration social enterprises. Academy of Management Journal, 58(6), 1658-1685.

Bel, C., \& Fageda, X. (2007). Why do local governments privatize public services? A survey of empirical studies. Local Government Studies, 33(4), 517-553.

Be'land, D., \& Koreh, M. (2019). Social insurance as fiscal policy and state-building tool: The development and politics of payroll contributions in Israel and Canada. Journal of Social Policy, $48(1), 1-20$.

Benish, A. (2018). The privatization of social services in Israel. In A. Paz-Fuchs, R. Mandelkern, \& I. Galnoor (Eds.), The privatization of Israel: The withdrawal of state responsibility (pp. 173-200). Palgrave-Macmillan.

Besharov, M. L., \& Smith, W. K. (2014). Multiple institutional logics in organizations: Explaining their varied nature and implications. Academy of Management Review, 39(3), 364-381.

Billis, D. (2010). Towards a theory of hybrid organizations. In D. Billis (Ed.), Hybrid organizations and the third sector (pp. 46-69). Palgrave Macmillan.

Blau, P. M. (1964). Exchange and power in social life. Wiley.

Borzaga, C., \& Tortia, E. (2006). Worker motivations, job satisfaction, and loyalty in public and nonprofit social services. Nonprofit and Voluntary Sector Quarterly, 35(2), 225-248.

Bryson, M. J., Crosby, B. C., \& Stone, M. M. (2006). The design and implementation of cross-sector collaborations: Propositions from the literature. Public Administration Review, 66, 44-55.

Buch, R., Kuvaas, B., \& Dysvik, A. (2019). The role of other orientation in reactions to social and economic leader-member exchange relationships. Journal of Organizational Behavior, 40(3), 296-310.

Buch, R., Kuvaas, B., Dysvik, A., \& Schyns, S. (2013). If and when social and economic leader-member exchange relationships predict follower work effort. Moderating Role of Work Motivation, 35(8), 725-739.

Burnley, C., Matthews, C., \& McKenzie, S. (2005). Devolution of services to children and families: The experience of NPOs in Nanaimo, British Columbia. Canada. Voluntas, 16(1), 69-87.

Cropanzano, R., \& Mitchell, M. S. (2005). Social exchange theory: An interdisciplinary review. Journal of Management, 31(6), 874-900.

Dysvik, A., Buch, R., \& Kuvaas, B. (2015). Knowledge donating and knowledge collecting: The moderating roles of social and economic LMX. Leadership and Organization Development Journal, 36(1), 35-53.

Emerson, R. M. (1976). Social exchange theory. Annual Review of Sociology, 2, 335-362.

Freenstra, R. A. (2018). Blurring the lines between civil society, volunteering and social movements. A reflection on redrawing boundaries inspired by the Spanish case. VOLUNTAS: International Journal of Voluntary and Nonprofit Organizations, 29, $1202-1215$.

Freund, A. (2005). Work attitudes of social workers across three sectors of welfare organizations. Journal of Social Service Research, 31(3), 69-92.

Freund, A., Kolton, G., \& Tzriker, A. (2019). Commitment to a career in social work; personal and organizational factors. Society \& Welfare, 39(4), 689-710. (Hebrew). 
Freund, A., \& Tzriker, A. (2016). Commitment to the profession of a social worker at the beginning of his career, and its connection to the type of organization, ambiguity and style of attachment. Society and Welfare, 36(4), 307-329. (Hebrew).

Gidron, B., Bar, M., \& Katz, H. (2004). The third sector in Israel: Between welfare state and civil society. Plenum.

Hasenfeld, Y., \& Gidron, B. (2005). Understanding multi-purpose hybrid voluntary organizations: The contributions of theories on civil society, social movements and non-profit organizations. Journal of Civil Society, 1(2), 97-112.

Heruti-Sober, T. (2018). News to 1,500 social workers: The distortion in their wages will be corrected, the conditions will be equalized. The Marker, 18 October. (Hebrew).

Hesse, A., Kreutzer, K., \& Diehl, M.-R. (2019). Dynamics of institutional logics in a cross-sector social partnership: The case of refugee integration in Germany. Journal of Business Ethics, 159(3), 679-704.

Israeli Association of Social Workers (2018). Expansion order Zchuton. Retrieved from https://www.socialwork.org.il/. (Hebrew).

Israeli Association of Social Workers (2018). Code of professional ethics of the social workers in Israel (Hebrew).

Itzick, M., \& Kagan, M. (2016). Intention to leave the profession: Welfare social workers compared to health care and community social workers in Israel. Journal of Social Service Research, 43(3), 346-357.

Jiang, H., Wang, Y., Chui, E., \& Xu, Y. (2019). Professional identity and turnover intentions of social workers in Beijing, China: The roles of job satisfaction and agency type. International Social Work, 62(1), 146-160.

Kagan, M., \& Itzick, M. (2017). Work-related factors associated with psychological distress among social workers. European Journal of Social Work, 22(1), 30-42.

Kim, P., Pinkley, R., \& Fragale, A. (2005). Power dynamics in negotiation. Academy of Management Review, 30(4), 799-822.

Klijn, E. H., \& Teisman, G. R. (2004). Public-private partnership: The right form at the wrong moment? An analysis of institutional and strategic obstacles. In A. Ghobadian, D. Gallear, N. O'Regan, \& H. Viney (Eds.), Public-private partnerships: Policy and experience (pp. 147-164). Palgrave Macmillan.

Kuvaas, B., Shore, L. M., Buch, R., \& Dysvik, A. (2020). Social and economic exchange relationships and performance contingency: Differential effects of variable pay and base pay. The International Journal of Human Resource, 31(3), 408-431.

Levine, S., \& White, P. E. (1961). Exchange as a conceptual framework for the study of interorganizational relationships. Administrative Science Quarterly, 5(4), 583-601.

Liu, X., \& Deng, J. (2011). Development of organizational commitment based on the social exchange theory. In: Paper presented at the International Conference on Management and Service Science (MASS). Wuhan, China.

Luo, M. S., \& Chui, E. W. T. (2020). Will material interest make social workers quit their job? A Meta-Analysis. Journal of Social Work, 20(3), 340-364.

McMullin, C., \& Skelcher, C. (2018). The impact of societal-level institutional logics on hybridity: Evidence from nonprofit organizations in England and France. VOLUNTAS: International Journal of Voluntary and Nonprofit Organizations, 29, 911-924.

Meyer, J. P., \& Parfyonova, N. M. (2010). Normative commitment in the workplace: A theoretical analysis and re-conceptualization. Human Resource Management Review, 20, 283-294.

Mikolajczak, P. (2020). Social enterprises' hybridity in the concept of institutional logics: Evidence from Polish NGOs. VOLUNTAS: International Journal of Voluntary and Nonprofit Organizations, $31,472-483$.
Milward, H. B., \& Provan, K. G. (2000). Governing the hollow state. Journal of Policy Administration Research and Theory, 10(2), $359-379$.

Nelson, N. (2005). Ideologies of aid, practice of power: Lessons for Medicaid managed care. Medical Anthropology Quarterly, 19(1), 102-122.

$\mathrm{Ng}$, I. Y. H. (2010). What if social workers were paid more? Administration in Social Work, 34(4), 351-360.

Ngoye, B., Sierra, V., \& Ysa, T. (2019). Different shades of gray: A priming experimental study on how institutional logics influence organizational actor judgment. Public Administration Review, 79(2), 256-266.

Oppenheim-Weller, S., Schwartz, E., \& Ben-Arieh, A. (2017). Child involvement in treatment planning and assessment in Israel. Child and Family Social Work, 22, 1302-1312.

Pache, A.-C., \& Santos, F. (2013). Inside the hybrid organization: Selective coupling as a response to competing institutional logics. Academy of Management Journal, 56(4), 972-1001.

Paz-Fuchs, A. (2018). Privatization, outsourcing, and employment relations in Israel. In A. Paz-Fuchs, R. Mandelkern, \& I. Galnoor (Eds.), The privatization of Israel: The withdrawal of state responsibility (pp. 283-310). Palgrave- Macmillan.

Perez, M. (2019). Transaction cost perspectives on cooperation: A study of hybrid through foundations lobbying in the EU. VOLUNTAS: International Journal of Voluntary and Nonprofit Organizations, 30(2), 408-421.

Schaufeli, W. B. (2006). The balance of give and take: Toward a social exchange model of burnout. RIPS/IRSP, 19(1), 75-119.

Schmid, H. (2020). The COVID-19 crisis and the political crisis as an opportunity for civil society organizations in Israel. ESPANET Israel, the Israeli national association of the European Network for Social Policy Analysis (Hebrew).

Schmid, H. (2013). Nonprofit human services: Between identity blurring and adaptation to changing environments. Administration in Social Work, 37(3), 242-256.

Schmid, H., \& Bar-Nir, D. (2001). The relationship between organizational properties and service effectiveness in residential boarding schools. Children and Youth Services Review, 23 (3), 243-271.

Schweitzer, D., Chianello, T., \& Kothari, B. (2013). Compensation in social work: Critical for satisfaction and a sustainable profession. Administration in Social Work, 37(2), 147-157.

Shim, W. S., Hwang, M. J., \& Lee, J. (2009). Professional identity, job satisfaction, and retention of licensed social workers in Korea. Asia Pacific Journal of Social Work and Development, 19(1), 82-95.

Shlosberg, I., Hermoni, I., \& Karmi, O. (2017). Application of the collective agreement - From vision to reality. Medio's, 84, 44-48. (Hebrew).

Shore, L. M., Coyle-Shapiro, J.A.-M., Chen, X.-P., \& Tetrick, L. E. (2009). Social exchange in work settings: Content, process, and mixed models. Management and Organization Review, 5(3), 289-302.

Shore, L. M., Tetrich, L. E., \& Barksdale, K. (2006). Social and economic exchange: Construct development and validation. Journal of Applied Social Psychology, 36(4), 837-867.

Smith, C. (2004). Trust and confidence: Making the moral case for social work. Social Work and Social Review, 11(3), 5-15.

Suh, J. (2018). Human capital inflow in nonprofits: Entry-level employees' sector shift. Nonprofit Management and Leadership, $28,471-489$.

Thornton, P. H., Ocasio, W., \& Lounsbury, M. (2012). The institutional logics perspective: A new approach to culture, structure, and process. Oxford University Press.

Vurro, C., Dacin, T., \& Perrini, F. (2010). Institutional antecedents of partnering for social change: How institutional logics shape 
cross-sector social partnerships. Journal of Business Ethics, 94, 39-53.

Wang, T. K. (2013). The impacts of the hollow state on organizational practices and individual attitudes in the federal government. Electronic Theses, Treatises and Dissertations. Paper 8658.

Warner, M. E. (2009). Civic government or market-based governance? The limits of privatization for rural local governments. Agriculture and Human Values, 26(1), 133-143.

Zhu, Y. (2012). Social exchange relationship, economic exchange relationship, in-role behavior: The mediating effect of job satisfaction. Asian Social Science, 8(8), 194-199.

Zychlinski, E., Lev, S.\& Kagan, M. (2020a). The ethical conflict of dual obligations amongst social workers: The role of organisational affiliation and seniority. The British Journal of Social Work, 50 (6), 1854-1870.

Zychlinski, E., Mahat- Shamir, M., Lavanda, O. \& Kagan, M. (2020b). Psychological distress and intention to leave the profession: The social and economic exchange mediating. The British Journal of Social Work, 51 (3), 816-830.

Publisher's Note Springer Nature remains neutral with regard to jurisdictional claims in published maps and institutional affiliations. 